\title{
A polymethoxyflavone from Laggera pterodonta induces apoptosis in imatinib-resistant K562R cells via activation of the intrinsic apoptosis pathway
}

\author{
Changshu Cao ${ }^{1,2}$, Bailian Liư ${ }^{3}$, Chengwu Zeng ${ }^{2}$, Yuhong Lư ${ }^{4}$ Shaohua Chen ${ }^{2}$, Lijian Yang ${ }^{2}$, Bo Li ${ }^{2}$, Yaolan Li ${ }^{3 *}$ \\ and Yangqiu $\mathrm{Li}^{2,5^{*}}$
}

\begin{abstract}
Background: Treatment with imatinib mesylate (IM) (a tyrosine kinase inhibitor) is the first line of standard care for patients newly diagnosed with CML. Despite the success of IM and other tyrosine kinase inhibitors (TKIs), chronic myeloid leukemia (CML) remains largely incurable, and a number of CML patients die due to Abl mutation-related drug resistance and blast crisis. 3, 5-Dihydroxy-6, 7, 3'4'-tetramethoxyflavone (DHTMF) is a polymethoxyflavone isolated from Laggera pterodonta which is a herbal medicine used to treat cancer in the Chinese folk. In the previous study, we found DHTMF demonstrated good antiproliferative activities against a number of cancer cell lines and induced the apoptosis of CNE cells in vitro in a time- and dose-dependent manner while exhibiting low cytotoxicity in the two normal cell lines Vero and EVC304. The aim of the present study was to evaluate the proliferation inhibition and apoptosis induced by DHTMF alone and in combination with IM in the IM-resistant CML cell line K562R.
\end{abstract}

Methods: Cell proliferation was assayed with the cell counting kit-8 (CCK8) method. The apoptosis percentage was determined by flow cytometry (FCM). Mitochondrial transmembrane potential was detected using FCM and confocal laser-scanning microscopy. The level of proteins involved in apoptosis was detected by Western blotting.

Results: DHTMF suppressed K562R cell viability in both time- and dose-dependent manners. DHTMF combined with IM enhanced the inhibitory effects and apoptosis in K562R cells as compared with DHTMF alone. DHTMF alone and in combination with IM significantly decreased the mitochondrial membrane potential and increased the levels of cleaved caspase-9, caspase-7, caspase-3, and PARP in K562R cells.

Conclusions: We demonstrated that DHTMF could inhibit IM-resistant K562R cell proliferation and induces apoptosis via the intrinsic mitochondrial apoptotic pathway. These results suggest that DHTMF may be a potential therapeutic drug with lower side effects against IM resistance in CML cells.

Keywords: DHTMF, Imatinib-resistant K562 cells, Apoptosis, Cell proliferation

\section{Background}

Chronic myeloid leukemia (CML) is a hematopoietic stem cell disorder that occurs due to t $(9 ; 22)$ (q34; q11) translocations. CML represents approximately $20 \%$ of all adult leukemia cases [1]. The aberrant Philadelphia chromosome has been reported to be the main cause of CML development due to fusion with the Bcr-Abl oncogene.

\footnotetext{
*Correspondence: liyaolan17@126.com; yangqiuli@hotmail.com ${ }^{3}$ Institute of Traditional Chinese Medicine \& Natural Products, College of Pharmacy, Jinan University, Guangzhou, China

${ }^{2}$ Institute of Hematology, Jinan University, Guangzhou 510632, China Full list of author information is available at the end of the article
}

The chimeric gene Bcr-Abl encodes a protein with constitutive tyrosine-kinase (TK) activity [2]. CML prognoses have markedly improved after the introduction of Abl tyrosine kinase inhibitors (TKIs). Since approved as frontline CML management in 2001, imatinib mesylate (IM) has been proven to be effective in achieving high remission rates and improving prognosis. However, up to 33\% of patients did not achieve an optimal response [3], because residual CML cells were generally present in the bone marrow microenvironment and then refractory to IM [4]. Unfortunately, most CML patients who were treated with IM undergone relapse once the drug was 
withdrawn, and Abl mutation-related drug resistance and blast crisis resulted in numerous CML patients death [5]. Next-generation TKIs, such as dasatinib and nilotinib, as well as other kinase inhibitors including Janus kinase 2 inhibitor and Bruton's tyrosine kinase (BTK) inhibitor, have been used to overcome IM-resistant cases [6,7]. Despite the increasing success of new TKIs, CML remains largely incurable, and the development of inducible drug resistance is a paramount problem in which patients failed respond to the drugs. How to treat the patients who were resistant to Bcr-Abl tyrosine kinase inhibitors is an important and urgent issue for clinical hematology. Thus, more efforts have been directly focused on developing new drugs to control CML with IM resistance.

Chinese herbal medicines traditionally used to treat cancer are an important source of potential anti-cancer agents [8-11]. Laggera pterodonta is an herbal medicine which is used for a long time in Chinese folk for the treatment of various inflammations as well as cancers [12]. Naturally occurring flavonoids have been proved to possess a wide range of biological activities including antitumor activity [13]. Studies have revealed that quite a few flavonoids could reverse drug resistance through different apoptosis pathways [14-16]. In our previous study, a polymethoxyflavone, 3,5-dihydroxy-6,7,3'4'-tetramethoxyflavone (DHTMF), isolated from Laggera pterodonta was found to possess good anti-cancer activity [17]. Recently, polymethoxyflavones are gaining increasing attention due to their promising anticancer potential. In this study, we investigated the proliferation inhibition and apoptosis induced by DHTMF alone and in combination with IM in the IM-resistant CML cell line K562R.

\section{Results}

\section{Effect of DHTMF on cell proliferation}

We first verified that the K562R cells we used are IMresistant CML cells. After K562 and K562R cells were treated with different concentrations of IM for $24 \mathrm{~h}$, their cell viability was determined by the CCK8 assay. The data indicated that IM preferentially inhibits the proliferation of IM-sensitive K562 cells. After the K562 and K562R cells were treated with $1 \mu \mathrm{mol} / \mathrm{L} \mathrm{IM}$ for $24 \mathrm{~h}$, the inhibitory ratio for the K562 cells was 69.75 , while that for K562R was only 13.99 (Figure 1). We calculated the $\mathrm{IC}_{50}$ (50\% inhibition concentration) for the $\mathrm{K} 562$ cells to be $0.43 \mu \mathrm{mol} / \mathrm{L}$, and the $\mathrm{IC}_{50}$ for the $\mathrm{K} 562 \mathrm{R}$ cells to be $6.23 \mu \mathrm{mol} / \mathrm{L}$, which indicated that $\mathrm{K} 562$ cells have a markedly lower $\mathrm{IC}_{50}$ compared with $\mathrm{K} 562 \mathrm{R}$ cells. The IM resistance fold-change of the K562R cells was 14.49.

To determine the inhibitory effects of DHTMF, K562R cells were treated with six concentrations of DHTMF for 24,48 , and $72 \mathrm{~h}$, and cell viability was determined by the CCK8 assay. When K562R cells were treated with DHTMF for 24,48 , and $72 \mathrm{~h}$, the inhibitory ratio increased with

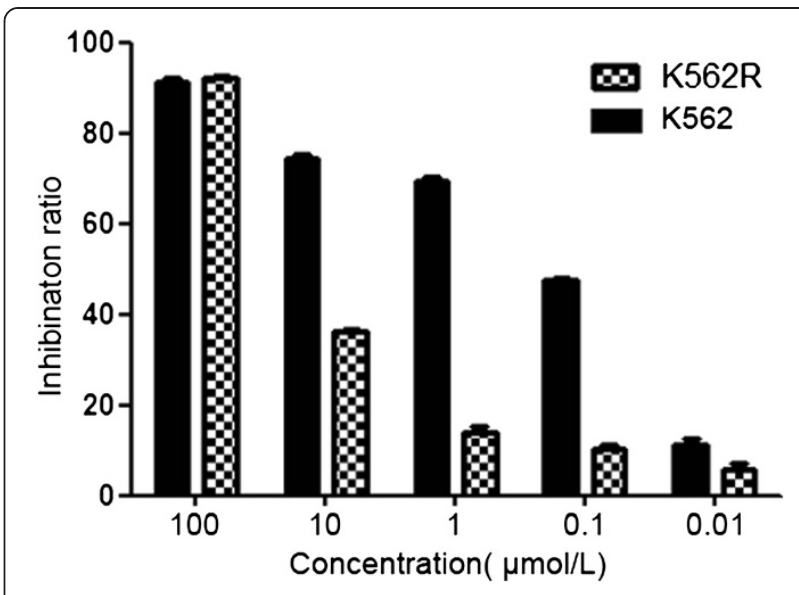

Figure 1 The inhibitory effect of IM in K562 and K562R cells at $24 \mathrm{~h}$.

increasing concentration $(p<0.05, p<0.01)$. DHTMF at concentrations of 24,48 , and $72 \mathrm{~h}$ exhibited inhibitory effects with $\mathrm{IC}_{50}$ concentrations of $7.85,5.78$, and $5.32 \mu \mathrm{g} / \mathrm{mL}$, respectively. When comparing with the same concentrations at $24 \mathrm{~h}$, the inhibitory ratio was also significantly increased $(p<0.05, p<0.01)$. As shown in Figure 2, these results suggest that DHTMF suppresses cell viability in a time- and dose-dependent manner.

To further observe the inhibitory effects of DHTMF on K562R cells in the presence or absence of IM, K562R cells were treated with different concentration combinations $(1 \mu \mathrm{mol} / \mathrm{L} \mathrm{IM}, 2.5 \mu \mathrm{g} / \mathrm{mL}$ DHTMF, $5 \mu \mathrm{g} / \mathrm{mL}$ DHTMF, $10 \mu \mathrm{g} / \mathrm{mL}$ DHTMF, $1 \mu \mathrm{mol} / \mathrm{L}$ IM $+2.5 \mu \mathrm{g} / \mathrm{mL}$ DHTMF, $1 \mu \mathrm{mol} / \mathrm{L} \mathrm{IM}+5 \mu \mathrm{g} / \mathrm{mL}$ DHTMF, and $1 \mu \mathrm{mol} / \mathrm{L}$ IM $+10 \mu \mathrm{g} / \mathrm{mL}$ DHTMF) for 24,48 , and $72 \mathrm{~h}$, and cell viability was determined by the CCK 8 assay. As shown in Figure 3 , inhibitory ratio was significantly increased by DHTMF alone and in combination with IM $(P<0.01)$. The inhibitory ratio was greater than $45 \%$ when $1 \mu \mathrm{mol} / \mathrm{L}$ IM was combined with $5 \mu \mathrm{g} / \mathrm{mL}$ DHTMF for $24 \mathrm{~h}$. Compared with the same concentration of DHTMF at the same time, the inhibitory activity was also increased in $\mathrm{K} 562 \mathrm{R}$ cells $(P<0.01)$. These results suggested that DHTMF combined with IM enhances the inhibitory effects of DHTMF on K562R cells.

\section{DHTMF alone and in combination with imatinib induces apoptosis in $\mathrm{K} 562 \mathrm{R}$ cells}

To investigate whether the inhibitory effects of DHTMF in $\mathrm{K} 562 \mathrm{R}$ cells is associated with apoptosis, treated K562R cells were labeled with AV and PI and analyzed by flow cytometry. Annexin V is an inner membrane protein with a strong affinity for phosphatidylserine. Surface staining of annexin $\mathrm{V}$ is used as a general indicator of apoptosis. As shown in Figure 4, most K562R cells were viable in 


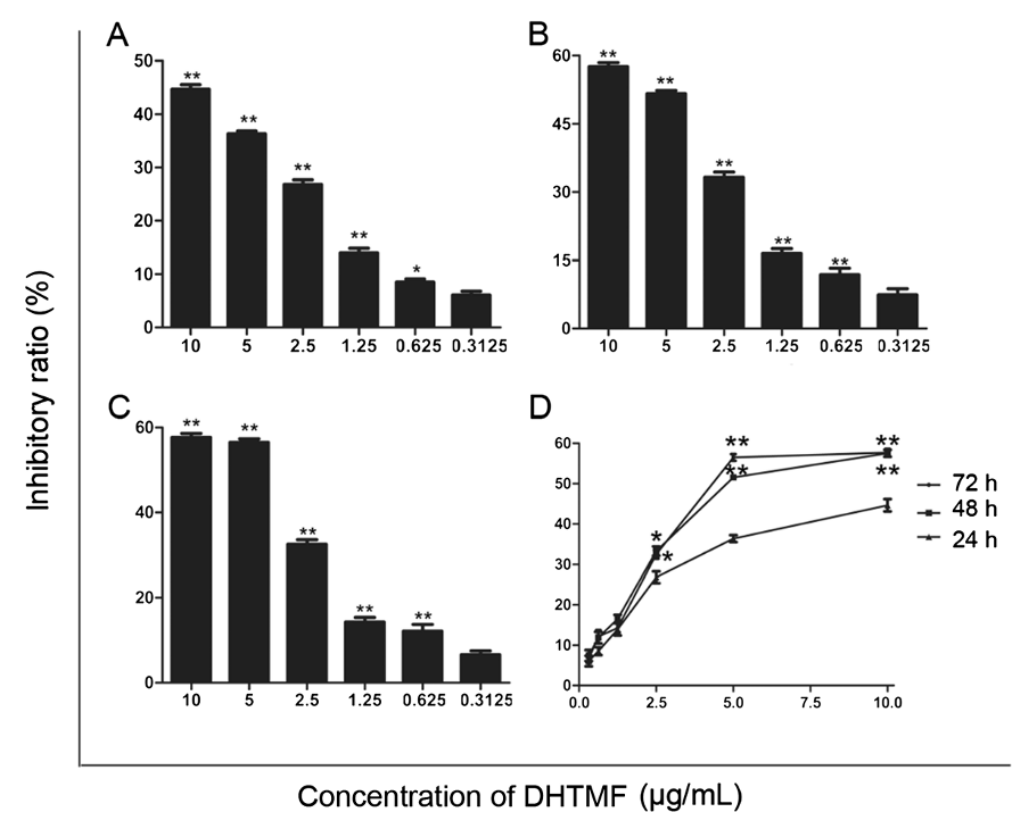

Figure 2 The inhibitory effect of DHTMF in K562R cells at different treatment times. A: 24 h, B: 48 h, C: 72 h. ${ }^{* *}, P<0.01 \mathrm{vs} .0 .3125 \mu \mathrm{g} / \mathrm{mL}$; D: ${ }^{*}, P<0.05,{ }^{* *}, P<0.01$ vs. the same concentration for $24 \mathrm{~h}$.

the control group following treatment with different concentration combinations $(1 \mu \mathrm{mol} / \mathrm{L} \mathrm{IM}, 5 \mu \mathrm{g} / \mathrm{mL}$ DHTMF, and $1 \mu \mathrm{mol} / \mathrm{L} \mathrm{IM}+5 \mu \mathrm{g} / \mathrm{mL}$ DHTMF) for $24 \mathrm{~h}$. However, after incubation with DHTMF alone or in combination with IM for $24 \mathrm{~h}$ (Figure 5), the cells displayed an increase

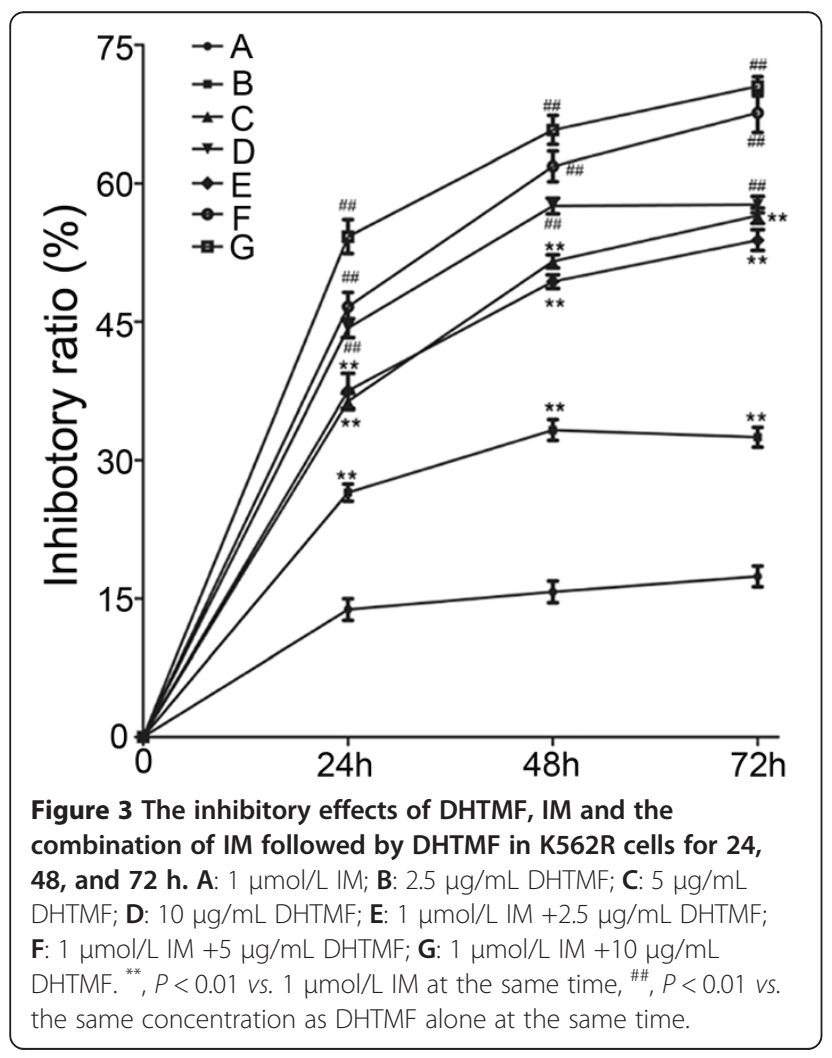

in the average apoptosis rate of the cells $\left(\mathrm{Q}_{4}, \mathrm{AV}\right.$ positive but PI negative) ranging from $4.5 \pm 0.57 \%$ for the control group and up to $5.4 \pm 0.28 \%, 32.6 \pm 0.14 \%$, and $47.9 \pm$ $0.01 \%$ for the treatment groups, respectively. K562R cells treated with $5 \mu \mathrm{g} / \mathrm{mL}$ DHTMF or $1 \mu \mathrm{mol} / \mathrm{L} \mathrm{IM}+5 \mu \mathrm{g} / \mathrm{mL}$ DHTMF had a pronounced increase in apoptosis as indicated by the increase in the AV+/PI - population ( $4.5 \%$ for the control versus $32.6 \%$ for $5 \mu \mathrm{g} / \mathrm{mL}$ DHTMF, $5.4 \%$ for $1 \mu \mathrm{mol} / \mathrm{L}$ IM vs. $47.9 \%$ for $1 \mu \mathrm{mol} / \mathrm{L}$ IM $+5 \mu \mathrm{g} / \mathrm{mL}$ DHTMF, and $32.6 \%$ for $5 \mu \mathrm{g} / \mathrm{mL}$ DHTMF vs. $47.9 \%$ for $1 \mu \mathrm{mol} / \mathrm{L} \mathrm{IM}+5 \mu \mathrm{g} / \mathrm{mL}$ DHTMF $(P<0.01, P<0.01$ and $P<0.01$, respectively).

\section{DHTMF induces the apoptosis of K562R cells via the mitochondrial apoptotic pathway}

To understand the underlying mechanism by which DHTMF alone and in combination with IM induces apoptosis, we investigated changes in the mitochondrial membrane potential and the level of proteins involved in apoptosis.

First, we explored the effects of DHTMF on mitochondrial membrane potential. K562R cells were cultured in different drug concentrations for $24 \mathrm{~h}$ and analyzed by flow cytometry and laser confocal microscopy following JC-1 staining (Figure $5 \mathrm{~A}, \mathrm{~B}$ ). Upon $5 \mu \mathrm{g} / \mathrm{mL}$ DHTMF or $1 \mu \mathrm{mol} / \mathrm{L} \mathrm{IM}+5 \mu \mathrm{g} / \mathrm{mL}$ DHTMF treatment, the number of cells displaying monomeric green fluorescence increased compared with untreated cells and those exposed to $1 \mu \mathrm{mol} / \mathrm{L}$ IM. These data indicated that the mitochondrial membrane potential is significantly decreased by the $5 \mu \mathrm{g} / \mathrm{mL}$ DHTMF and $1 \mu \mathrm{mol} / \mathrm{L} \mathrm{IM}+5 \mu \mathrm{g} / \mathrm{mL}$ DHTMF 


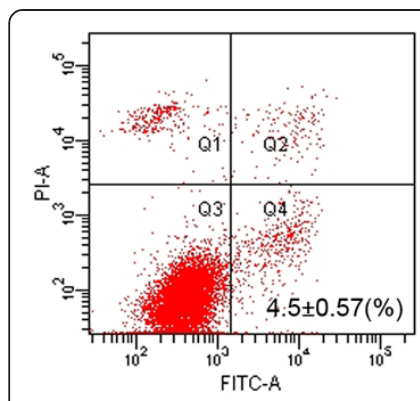

A: Control

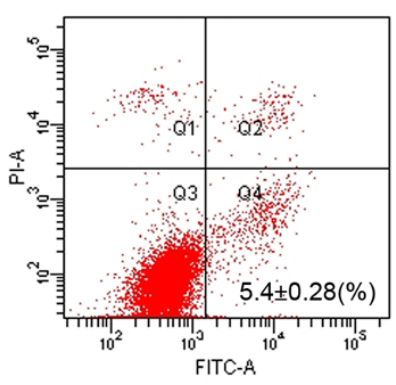

$\mathrm{B}: 1 \mu \mathrm{mol} / \mathrm{L} \mathrm{IM}$

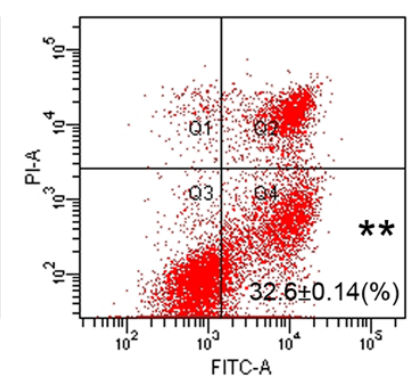

C:5 $\mu \mathrm{g} / \mathrm{mL}$ DHTMF

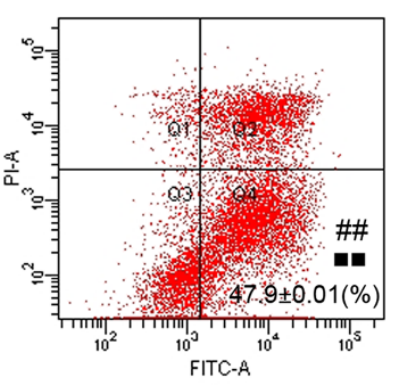

$\mathrm{D}: 1 \mu \mathrm{mol} / \mathrm{L} \mathrm{IM}+5 \mu \mathrm{g} / \mathrm{mL}$

Figure 4 Induction of apoptosis by DHTMF alone or combination of IM in K562R cells for $24 \mathrm{~h}$ treatment. A: Control; B: $1 \mu \mathrm{mol} / \mathrm{L} \mid \mathrm{M}$; C: $5 \mu \mathrm{g} / \mathrm{mL}$ DHTMF; D: $1 \mu \mathrm{mol} / \mathrm{L} \mathrm{IM}+5 \mu \mathrm{g} / \mathrm{mL}$ DHTMF. $P>0.05, \mathrm{~B}$ vs. $\mathrm{A}_{;}^{* *}, P<0.01$ vs. A; ${ }^{* \#}, P<0.01$ vs. B, ${ }^{-4}, P<0.01$ vs. C.

treatments $(P<0.01, P<0.01$ and $P<0.01$, respectively). This finding suggests that DHTMF alone and in combination with IM disrupts the mitochondrial membrane potential, resulting in the cytosolic accumulation of monomeric JC-1, which is an indicator of apoptosis via activation of the intrinsic pathway.

Caspases are crucial players in the induction of apoptotic cell death. Caspase-9 is an initiator caspase that has been implicated in the mitochondria-dependent pathway. To assess the effects of DHTMF alone and in combination with IM on the cleavage of caspases and PARP, cells were treated with different drug concentrations for $24 \mathrm{~h}$, and total cell lysates were prepared for Western blot analysis. As shown in Figure 6, DHTMF affected the increase in the level of cleaved caspase-9, caspase-7, caspase-3, and PARP in K562R cells. In K562R cells treated with $5 \mu \mathrm{g} / \mathrm{mL}$ DHTMF and $1 \mu \mathrm{mol} / \mathrm{L} \mathrm{IM}+5 \mu \mathrm{g} / \mathrm{mL}$ DHTMF, the immunoreactivity of the cleaved caspases and PARP were dramatically increased $(P<0.01, P<0.01$ and $P<0.01$, respectively). These results indicate that DHTMF alone and in combination with IM induces apoptosis in K562R cells via caspase-3, caspase-9, and caspase-7 activation, and DHTMF-induced apoptosis is associated with the mitochondria-dependent pathway.

\section{Discussion}

Treatment with IM is the standard of care for patients newly diagnosed with CML, while several second generation inhibitors, such as dasatinib and nilotinib, have become available with the promise of overcoming some

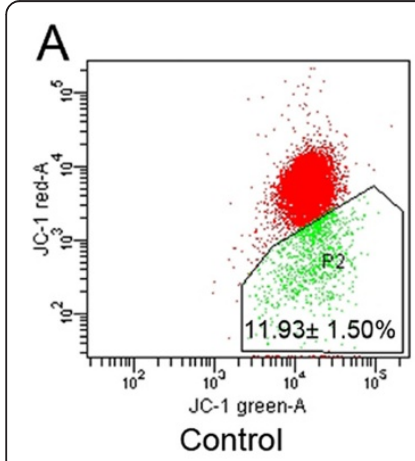

B

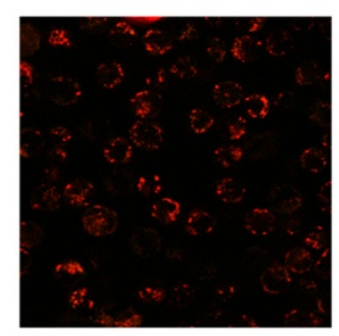

Control
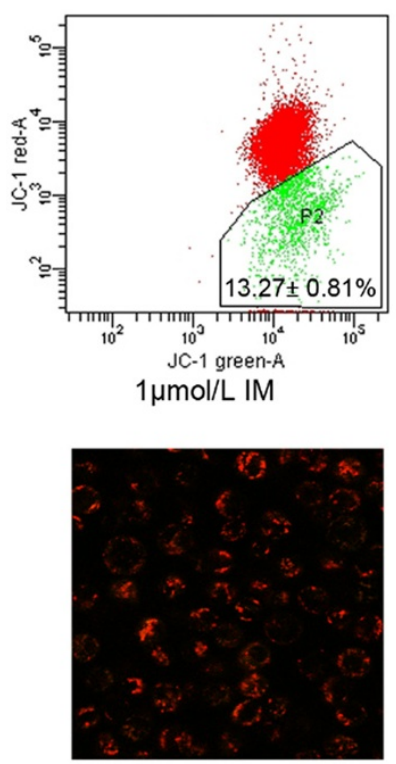

$1 \mu \mathrm{mol} / \mathrm{L} \mathrm{IM}$
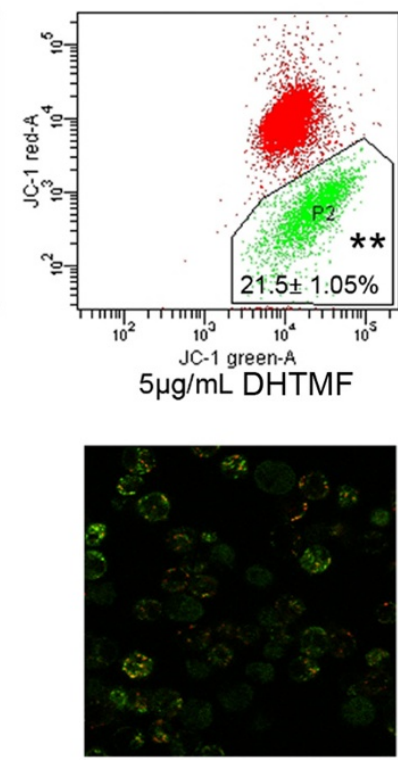

$5 \mu \mathrm{g} / \mathrm{mL}$ DHTMF
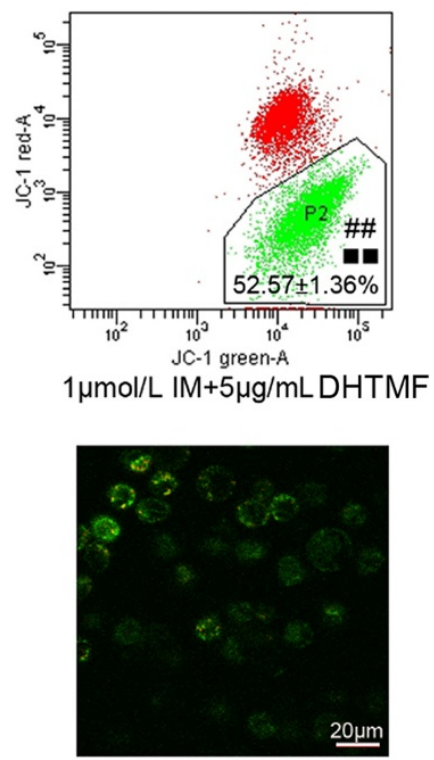

$1 \mu \mathrm{mol} / \mathrm{L} \mathrm{IM}+5 \mu \mathrm{g} / \mathrm{mLDHTMF}$

Figure 5 DHTMF alone or combination of IM induces mitochondria dysfunction in K562R cells. A: Cells were stained with JC-1 dye and analyzed by flow cytometry. ${ }^{* *}, P<0.01$ vs. Control, ${ }^{\#}, P<0.01$ vs. $1 \mu \mathrm{mol} / \mathrm{L} \mathrm{IM}, \boldsymbol{\mathbf { }}^{-}, P<0.01 \mathrm{vs} .5 \mathrm{\mu g} / \mathrm{mL}$ DHTMF. B: DHTMF induces mitochondria dysfunction on K562R cells. Cells were analyzed with a laser confocal microscope, Bar $=20 \mu \mathrm{m}$. 

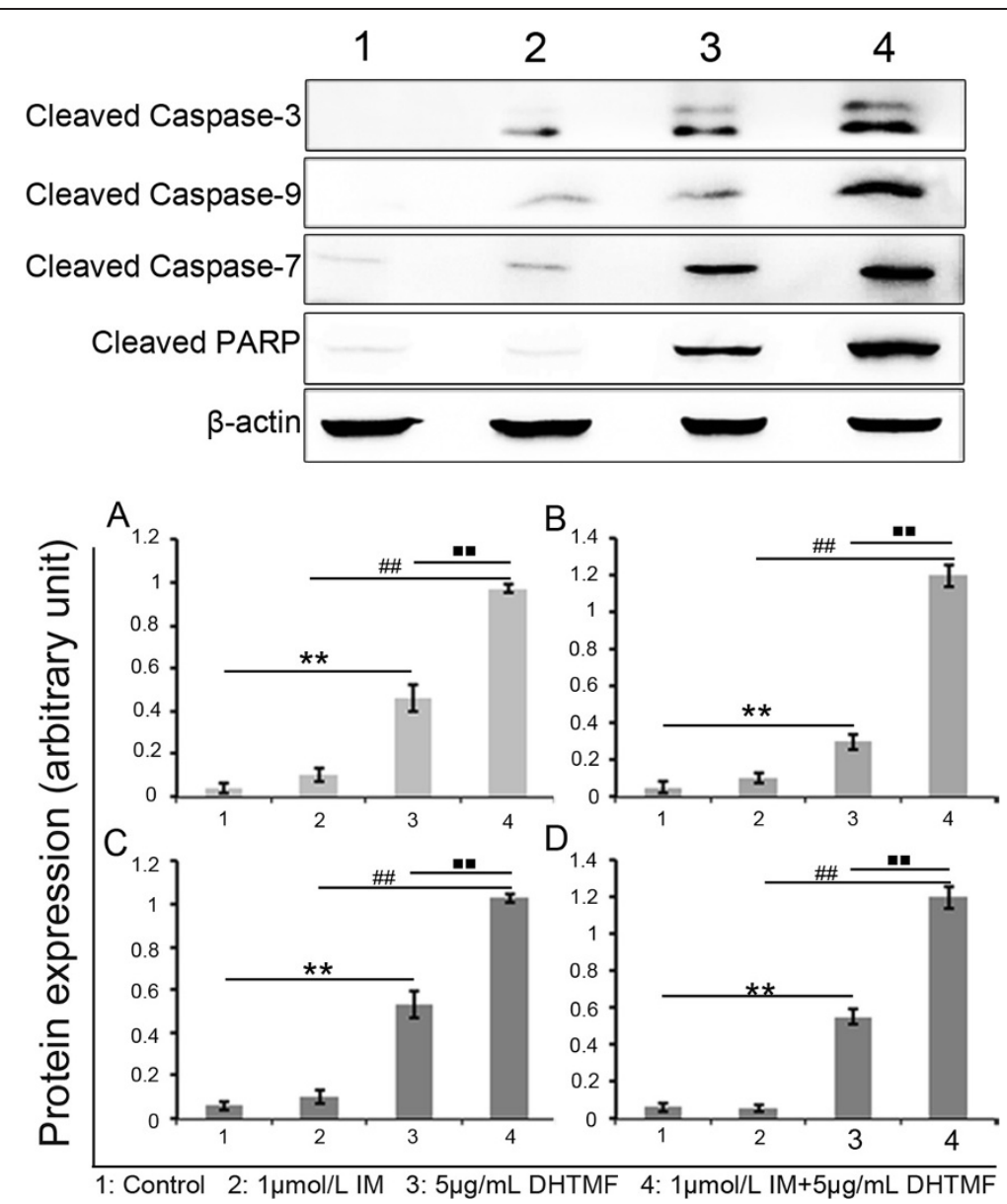

Figure 6 Western blot analysis in K562R cells. The relative expression level of the cleaved proteins was analyzed for caspase-3 (A), caspase-9 (B), caspase-7 (C) and PARP (D). $\beta$-actin was used as a loading control. The results are presented as the ratio of cleaved proteins compared to $\beta$-actin intensities. ${ }^{* *}, P<0.01$ vs. Control, ${ }^{\#}, P<0.01$ vs. $1 \mu \mathrm{mol} / \mathrm{L} \mathrm{IM},{ }^{-*}, P<0.01$ vs. $5 \mu \mathrm{g} / \mathrm{mL}$ DHTMF.

of the mutations associated with acquired resistance in these patients [18]. However, primary TKI therapy resistance and relapse due to the persistence of leukemic stem cells (LSCs) remain a major clinical problem. Moreover, TKI monotherapy is not curative. Recently, combination therapies such as the dual-targeting of the Bcr-Abl and JAK2 activities have been shown to lead to more effective disease eradication, particularly for CML patients at high risk for TKI resistance and disease progression $[19,20]$. Natural products, such as oridonin, which has been shown to induce the apoptosis of $t(8 ; 21)$ acute myeloid leukemic (AML) cells and inhibit the activity of c-Kit (+) leukemia-initiating cells [21,22], have been considered to play an important role in treating cancer and drug resistance, and they are promising and safe antitumor agents due to their natural origin. DHTMF is a polymethoxyflavone isolated from Laggera pterodonta that is a traditional herbal medicine. In a previous study, DHTMF demonstrated antiproliferative activities against a number of tumor cell lines and induced the apoptosis of CNE cells in vitro in a time- and dose-dependent manner while exhibiting low cytotoxicity in the two normal cell lines Vero and EVC304 [17]. Therefore, in this study, we used DHTMF in IM-resistant K562 cells (K562R) to investigate its anti-tumor effect. According to this finding, it would be interesting to characterize the effects of DHTMF in anti-leukemia therapy, particularly for the drug resistance of refractory leukemia. In this study, we analyzed the effects of DHTMF in IM-resistant K562 cells (K562R) and found that DHTMF alone or in combination with IM could significantly inhibit proliferation in a time- and dose-dependent manner. As such, the inhibitory ratio was $36.36 \%$ when $5 \mu \mathrm{g} / \mathrm{mL}$ DHTMF was used alone for $24 \mathrm{~h}$, while $5 \mu \mathrm{g} / \mathrm{mL}$ DHTMF combined with $1 \mu \mathrm{g} / \mathrm{mL}$ IM could increase the inhibitory activity to $46.63 \%$. These results suggest that DHTMF indeed has inhibitory effects in K562R cells and at the same time improves the sensitivity of K562R cells to IM. By flow cytometry, we confirmed that the percentage of apoptotic cells was significantly increased when $\mathrm{K} 562 \mathrm{R}$ cells were treated with $5 \mu \mathrm{g} / \mathrm{mL}$ 
DHTMF or $1 \mu \mathrm{mol} / \mathrm{L} \mathrm{IM}+5 \mu \mathrm{g} / \mathrm{mL}$ DHTMF for $24 \mathrm{~h}$. These findings indicate that DHTMF alone or in combination with IM inhibits cell proliferation by inducing apoptosis in K562R cells. There are two main apoptosis pathways: the extrinsic death receptor pathway and the intrinsic mitochondrial pathway [23]. Many polymethoxyflavone induce apoptosis via the mitochondrial apoptosis pathway [24-26]. To further investigate the potential mechanisms of action involved using apoptosis-related analysis, we first observed changes in the mitochondrial membrane potential by flow cytometry and laser confocal microscopy. The results showed that $5 \mu \mathrm{g} / \mathrm{mL}$ DHTMF and $1 \mu \mathrm{mol} / \mathrm{L} \mathrm{IM}+5 \mu \mathrm{g} / \mathrm{mL}$ DHTMF for $24 \mathrm{~h}$ significantly decrease the mitochondrial membrane potential. These results are consistent with the findings of previous studies in which DHTMF was shown to induce the apoptosis of CNE cells in vitro in a time- and dose-dependent manner [17]. These changes suggest that DHTMF is likely to induce apoptosis via the mitochondrial pathway. Caspases are crucial players in the induction of apoptotic cell death. Caspase- 9 is an initiator caspase that has been implicated in the mitochondria-dependent pathway [27]. In this study, we demonstrated that DHTMF alone or in combination with IM induces the cleavage of caspase- 9 , caspase-3, caspase-7, and PARP in DHTMF-treated K562R cells. DHTMF also markedly increased the levels of cleaved caspases and PARP, indicating that the apoptosis mechanism in DHTMF-treated K562R cells might be mediated by activation of the mitochondrial apoptotic pathway and subsequently activate the caspase pathway. Further study is required to elucidate additional mechanisms underlying DHTMF function and determine the exact molecular mechanisms of action of DHTMF in CML cells with IM resistance.

\section{Conclusions}

We demonstrated for the first time that DHTMF alone or in combination with IM inhibits IM-resistant K562R cell proliferation and induces apoptosis via the intrinsic mitochondrial apoptotic pathway. Moreover, DHTMF can improve the sensitivity of K562R to IM. These findings suggest that DHTMF may be a potential therapeutic drug with few side effects in reversing IM-resistance in CML. Whether DHTMF has other effects on Abl-mutated CML cells is worth investigating.

\section{Methods}

Polymethoxyflavone, cell, and reagents

3,5-Dihydroxy-6,7,3',4'-tetramethoxyflavone (DHTMF) was isolated from Laggera pterodonta, and its structure was identified with spectroscopic methods [28]. IMsensitive K562 cells (Institutes for Biological Sciences Cell Resource Center, Chinese Academy of Sciences, Shanghai, China) harboring $210 \mathrm{kDa}$ wild-type Bcr-Abl were grown in RPMI 1640 medium (Gibco-BRL, Grand Island, NY, USA) supplemented with $10 \%$ fetal calf serum (FCS) (Sijiqing Co., Hangzhou, China) and maintained in a humidified incubator at $37^{\circ} \mathrm{C}$ and $5 \% \mathrm{CO}_{2}$. IM-resistant K562R cells (provided by Prof. Jingxuan Pan, Sun Yat-sen University, Guangzhou, China) harboring $210 \mathrm{kDa}$ wildtype Bcr-Abl were routinely maintained in the same medium containing $5 \mu \mathrm{mol} / \mathrm{L}$ IM [29]. Three days before the experiments were performed, IM was no longer added to the media for cell culture.

\section{Cell proliferation assays}

The proliferation of K562R and K562 cells was indirectly assayed using the CCK8 kit (Dojindo, Japan), which stains living cells. Approximately $1 \times 10^{5} \mathrm{~K} 562 \mathrm{R}$ and $\mathrm{K} 562$ cells in $1 \mathrm{~mL}$ with $0.1,1,10,100,1,000 \mu \mathrm{mol} / \mathrm{L}$ IM or different concentrations of DHTMF alone or in combination with IM were incubated in triplicate in 96-well plates. At 24, 48 , and $72 \mathrm{~h}$, the CCK8 reagent $(10 \mu \mathrm{L})$ was added to each well, and the cells were incubated at $37^{\circ} \mathrm{C}$ for $6 \mathrm{~h}$. The optical density at $450 \mathrm{~nm}$ was measured using an automatic microplate reader (Synergy4; Bio-Tek, Winooski, VT, USA). $\mathrm{IC}_{50}$ values were determined by plotting compound concentration versus cell viability.

\section{Apoptosis analysis}

At $24 \mathrm{~h}, \mathrm{~K} 562 \mathrm{R}$ cells were treated with or without $1 \mu \mathrm{mol} / \mathrm{L} \mathrm{IM}, 5 \mu \mathrm{g} / \mathrm{mL}$ DHTMF, or $1 \mu \mathrm{mol} / \mathrm{L} \mathrm{IM}+5 \mu \mathrm{g} / \mathrm{mL}$ DHTMF. The cells were collected and then prepared with FITC-labeled anti-annexin-V (anti-AV, BD Pharmingen, San Diego, CA, USA) and propidium iodide (PI, Kaiji, Nanjing, China) according to the manufacturer's protocol and measured by flow cytometry (Beckman Coulter, Fullerton, CA, USA). The data were analyzed using Windows MDI 2.9 software.

\section{Detection of mitochondrial transmembrane potential using flow cytometry and confocal laser-scanning microscopy}

Changes in mitochondrial potential were detected by using $5,5^{\prime}, 6,6^{\prime}$-tetrachloro-1,1',3,3' tetraethyl benzimidazolyl carbocyanine iodide/chloride (JC-1), a cationic dye that exhibits potential-dependent accumulation in mitochondria. These changes were indicated by a fluorescence emission shift from red $(590 \mathrm{~nm})$ to green $(525 \mathrm{~nm})$, and they were analyzed by flow cytometry. At $24 \mathrm{~h}, \mathrm{~K} 562 \mathrm{R}$ cells were treated with or without $1 \mu \mathrm{mol} / \mathrm{L} \mathrm{IM}, 5 \mu \mathrm{g} / \mathrm{mL}$ DHTMF, and $1 \mu \mathrm{mol} / \mathrm{L} \mathrm{IM}+5 \mu \mathrm{g} / \mathrm{mL}$ DHTMF. The cells were collected, washed with phosphate-buffered saline (PBS), and analyzed on a flow cytometer. The \%Parent green fluorescence cells was calculated for each treatment. At $24 \mathrm{~h}$, K562R cells were treated with or without $1 \mu \mathrm{mol} / \mathrm{L} \mathrm{IM}$, $5 \mu \mathrm{g} / \mathrm{mL}$ DHTMF, and $1 \mu \mathrm{mol} / \mathrm{L} \mathrm{IM}+5 \mu \mathrm{g} / \mathrm{mL}$ DHTMF. The cells were collected, washed twice with PBS, and 
stained with JC-1 dye staining. Changes in the mitochondrial transmembrane potential of the cells after JC-1 dye staining were observed with a confocal laser-scanning microscope (LSM 510 META DuoScan; Carl Zeiss, Germany).

\section{Preparation and analysis of cell lysates by immunoblotting}

At $24 \mathrm{~h}, \mathrm{~K} 562 \mathrm{R}$ cells were treated with or without $1 \mu \mathrm{mol} / \mathrm{L}$ IM or $5 \mu \mathrm{g} / \mathrm{mL}$ DHTMF or their combination and were harvested and western blotting was carried out Protein quantification was performed according to conventional methods. Protein samples $(30 \mu \mathrm{g})$ were boiled with $5 \times$ loading buffer at $100^{\circ} \mathrm{C}$ for $5 \mathrm{~min}$ before being loaded, and they were then electrophoresed in a $12 \%$ SDS-PAGE gel at $80 \mathrm{~V}$ for $30 \mathrm{~min}$ followed by $120 \mathrm{~V}$ for $60 \mathrm{~min}$ (Bio-Rad). The separated proteins were transferred onto equilibrated PVDF membranes (Invitrogen) using a tank system (Bio-Rad). After blocking with 5\% skim milk in TBST for $1 \mathrm{~h}$, the membrane was incubated with individual primary antibodies including $\beta$-catenin (mouse anti-actin antibody, 1:1,000 dilution, Lianke, Hangzhou, China), cleaved caspase-3, cleaved caspase-9, cleaved caspase-7 and cleaved PARP (1:1,000 dilution, Cell signaling, Cleaved Caspase Antibody Sampler Kit Cat. No. \#9929) at $4^{\circ} \mathrm{C}$ overnight followed by incubation with goat anti-rabbit or donkey anti-mouse IgG antibodies (Cell signaling, Cleaved Caspase Antibody Sampler Kit Cat. No. \# 9929; Lianke, Hangzhou, China). Immunoreactive proteins were visualized by chemiluminescence (Lianke, Hangzhou, China), and images were obtained with a Vilber Lourmat system (UVI, UK). The protein expression level was calculated with image quantitative analysis software using $\beta$-actin as a reference gene.

\section{Statistical analysis}

Statistical significance was evaluated by one-way ANOVA using SPSS 11.5 statistical software. The results were considered significant at $\mathrm{p}$ value less than 0.05 .

\section{Abbreviations}

TKIs: Tyrosine kinase inhibitors; DHTMF: 3,5-hydroxy-6,7,3',4'tetramethoxyflavone; IM: Imatinib mesylate; CCK8: Counting kit-8; FCM: Flow cytometry; CML: Chronic myeloid leukemia; TK: Tyrosine-kinase; BTK: Bruton's tyrosine kinase; FCS: Fetal calf serum; PI: Propidium iodide; JC-1:

5,5',6,6'-tetrachloro-1,1',3,3' tetraethyl benzimidazolyl carbocyanine iodide/ chloride; K562R: IM-resistant K562 cells.

\section{Competing interests}

The authors declare that they have no competing interests.

\section{Authors' contributions}

YQL and YLL directed and conceived the study. CSC performed the cell proliferation assays, apoptosis analysis and immunoblotting. BLL and YLL isolated HTMF. CWZ, YHL, SHC and BL helped perform experiments, and LY performed cell culture. YQL and CSC coordinated the study and helped draft the manuscript. All authors performed experiments. All authors reviewed and assisted in revising the manuscript. All authors read and approved the final manuscript.

\section{Acknowledgements}

The study was supported by grants from the National Natural Science Foundation of China (nos. 81270604 and U1301226), the Natural Science Foundation of Guangdong Province, China (S2013020012863), the Guangdong Science \& Technology Project (2012B050600023), the Medical Science Foundation of Guangdong Province (A2014370) and the Open Research Program of Key Laboratory of Regenerative Biology, Chinese Academy of Sciences.

\section{Author details}

'Department of Human Anatomy, Medical School of Jinan University, Guangzhou 510632, China. ${ }^{2}$ Institute of Hematology, Jinan University, Guangzhou 510632, China. ${ }^{3}$ Institute of Traditional Chinese Medicine \& Natural Products, College of Pharmacy, Jinan University, Guangzhou, China. ${ }^{4}$ Department of Hematology, the First Affiliated Hospital of Jinan University, Guangzhou 510632, China. ${ }^{5}$ Key Laboratory for Regenerative Medicine of Ministry of Education, Jinan University, Guangzhou 510632, China.

Received: 29 October 2014 Accepted: 22 November 2014

Published online: 05 December 2014

\section{References}

1. Goldman JM, Melo JV: Chronic myeloid leukemia-advances in biology and new approaches to treatment. N Engl J Med 2003, 349(15):1451-1464.

2. Stam K, Heisterkamp N, Reynolds FH Jr, Groffen J: Evidence that the phl gene encodes a 160,000-dalton phosphoprotein with associated kinase activity. Mol Cell Biol 1987, 7(5):1955-1960.

3. Bhamidipati PK, Kantarijan H, Cortes J, Cornelison AM, Jabbour E: Management of imatinib-resistant patients with chronic myeloid leukemia. Ther Adv Hematol 2013, 4(2):103-117.

4. Okabe S, Tauchi T, Katagiri S, Tanaka Y, Ohyashiki K: Combination of the ABL kinase inhibitor imatinib with the Janus kinase 2 inhibitor TG101348 for targeting residual BCR-ABL-positive cells. J Hematol Oncol 2014, 7(1):37.

5. Ross DM, Branford S, Seymour JF, Schwarer AP, Arthur C, Yeung DT, Dang P, Goyne JM, Slader C, Filshie RJ, Mills AK, Melo JV, White DL, Grigg AP, Hughes TP: Safety and efficacy of imatinib cessation for CML patients with stable undetectable minimal residual disease: results from the TWISTER study. Blood 2013, 122(4):515-522.

6. Akinleye A, Chen Y, Mukhi N, Song Y, Liu D: Ibrutinib and novel BTK inhibitors in clinical development. J Hematol Oncol 2013, 6:59.

7. Mealing S, Barcena L, Hawkins N, Clark J, Eaton V, Hirji I, Davis C: The relative efficacy of imatinib, dasatinib and nilotinib for newly diagnosed chronic myeloid leukemia: a systematic review and network metaanalysis. Exp Hematol Oncol 2013, 2(1):5.

8. Zhao B, Hu M: Gallic acid reduces cell viability, proliferation, invasion and angiogenesis in human cervical cancer cells. Oncol Lett 2013, 6(6):1749-1755.

9. Koppikar SJ, Choudhari AS, Suryavanshi SA, Kumari S, Chattopadhyay S, Kaul-Ghanekar R: Aqueous cinnamon extract (ACE-c) from the bark of Cinnamomum cassia causes apoptosis in human cervical cancer cell line (SiHa) through loss of mitochondrial membrane potential. BMC Cancer 2010, 10:210.

10. Chen Y, Zhu J, Zhang W: Antitumor effect of traditional Chinese herbal medicines against lung cancer. Anti-Cancer Drugs 2014, 25(9):983-991

11. Li C, Sun BQ, Gai XD: Compounds from Chinese herbal medicines as reversal agents for P-glycoprotein-mediated multidrug resistance in tumours. Clin Transl Oncol 2014, 16(7):593-598.

12. Zhou CX, Wu DY, Li XP, Wu YH, Zhao J, Dong N, Yu RM, Wei W, Zheng QX, Sun HD, Hao XJ, Zhao Y: [Research progress in Laggera medicinal plants]. Zhongguo Zhong Yao Za Zhi 2006, 31(14):1133-1140.

13. Ravishankar D, Rajora AK, Greco F, Osborn HM: Flavonoids as prospective compounds for anti-cancer therapy. Int I Biochem Cell Biol 2013, 45(12):2821-2831

14. Hwang KA, Park MA, Kang NH, Yi BR, Hyun SH, Jeung EB, Choi KC: Anticancer effect of genistein on BG-1 ovarian cancer growth induced by 17 beta-estradiol or bisphenol A via the suppression of the crosstalk between estrogen receptor alpha and insulin-like growth factor-1 receptor signaling pathways. Toxicol Appl Pharmacol 2013, 272(3):637-646. 
15. Han YQ, Cao $L$, Hao HJ, Shi YJ: [Effects of quercetin on multidrug resistance and expression of related genes in human erythroleukemic K562/a cells]. Zhongguo Shi Yan Xue Ye Xue Za Zhi 2011, 19(4):884-889.

16. Schumacher M, Hautzinger A, Rossmann A, Holzhauser S, Popovic D, Hertrampf A, Kuntz S, Boll M, Wenzel U: Chrysin blocks topotecan-induced apoptosis in Caco-2 cells in spite of inhibition of ABC-transporters. Biochem Pharmacol 2010, 80(4):471-479.

17. Cao CH, SW LY, Wand H, Gao MY: 3, 5-Hydroxy-6, 7, 3', 4'-tetramethoxyflavone Isolated From Laggera pterodonta Induces CNE Cell Apoptosis. Prog Biochem Biophysics 2011, 38(3):254-261.

18. Olshen A, Tang M, Cortes J, Gonen M, Hughes T, Branford S, QuintasCardama A, Michor F: Dynamics of chronic myeloid leukemia response to dasatinib, nilotinib, and high-dose imatinib. Haematologica 2014. [Epub ahead of print].

19. Lin H, Chen M, Rothe K, Lorenzi MV, Woolfson A, Jiang X: Selective JAK2/ABL dual inhibition therapy effectively eliminates TKI-insensitive CML stem/progenitor cells. Oncotarget 2014, 5(18):8637-8650.

20. Kampa-Schittenhelm KM, Heinrich MC, Akmut F, Dohner H, Dohner K, Schittenhelm MM: Quizartinib (AC220) is a potent second generation class III tyrosine kinase inhibitor that displays a distinct inhibition profile against mutant-FLT3, -PDGFRA and -KIT isoforms. Mol Cancer 2013, 12:19.

21. Zhou GB, Kang H, Wang L, Gao L, Liu P, Xie J, Zhang FX, Weng XQ, Shen ZX, Chen J, Gu LJ, Yan M, Zhang DE, Chen SJ, Wang ZY, Chen Z: Oridonin, a diterpenoid extracted from medicinal herbs, targets AML1-ETO fusion protein and shows potent antitumor activity with low adverse effects on $\mathrm{t}(8 ; 21)$ leukemia in vitro and in vivo. Blood 2007, 109(8):3441-3450.

22. Zhen T, Wu CF, Liu P, Wu HY, Zhou GB, Lu Y, Liu JX, Liang Y, Li KK, Wang YY, Xie YY, He MM, Cao HM, Zhang WN, Chen LM, Petrie K, Chen SJ, Chen $Z$ : Targeting of AML1-ETO in $\mathrm{t}(8 ; 21)$ leukemia by oridonin generates a tumor suppressor-like protein. Sci Transl Med 2012, 4(127):127ra138

23. Wajant $\mathrm{H}$ : The Fas signaling pathway: more than a paradigm. Science 2002, 296(5573):1635-1636.

24. Wang J, Duan Y, Zhi D, Li G, Wang L, Zhang H, Gu L, Ruan H, Zhang K, Liu Q, Li S, Ho CT, Zhao H: Pro-apoptotic effects of the novel tangeretin derivate 5-acetyl-6,7,8,4'-tetramethylnortangeretin on mcf-7 breast cancer cells. Cell Biochem Biophys 2014, 70(2):1255-1263.

25. Dong Y, Cao A, Shi J, Yin P, Wang L, Ji G, Xie J, Wu D: Tangeretin, a citrus polymethoxyflavonoid, induces apoptosis of human gastric cancer AGS cells through extrinsic and intrinsic signaling pathways. Oncol Rep 2014, 31(4):1788-1794.

26. Meng FM, Yang JB, Yang $C H$, Jiang $Y$, Zhou YF, Yu B, Yang H: Vitexicarpin induces apoptosis in human prostate carcinoma PC-3 cells through G2/M phase arrest. Asian Pac J Cancer Prev 2012, 13(12):6369-6374.

27. Zou H, Li Y, Liu X, Wang X: An APAF-1.cytochrome c multimeric complex is a functional apoptosome that activates procaspase-9. J Biol Chem 1999, 274(17):11549-11556.

28. Liu B, Zhang T, Zhang X, Ye W, Li Y: Chemical constituents of Laggera pterodonta. Zhongguo Zhong Yao Za Zhi 2010, 35(5):602-606.

29. Shen Q, Liu S, Chen Y, Yang L, Chen S, Wu X, Li B, Lu Y, Zhu K, Li Y: Proliferation inhibition and apoptosis induction of imatinib-resistant chronic myeloid leukemia cells via PPP2R5C down-regulation. I Hematol Oncol 2013, 6:64

doi:10.1186/s12935-014-0137-1

Cite this article as: Cao et al: A polymethoxyflavone from Laggera pterodonta induces apoptosis in imatinib-resistant $\mathrm{K} 562 \mathrm{R}$ cells via activation of the intrinsic apoptosis pathway. Cancer Cell International 2014 14:137.

\section{Submit your next manuscript to BioMed Central and take full advantage of:}

- Convenient online submission

- Thorough peer review

- No space constraints or color figure charges

- Immediate publication on acceptance

- Inclusion in PubMed, CAS, Scopus and Google Scholar

- Research which is freely available for redistribution 